\title{
GOMMENTARIES
}

\section{TIME LIMITS AS INCENTIVES IN AN ADVERSARY SYSTEM}

\section{Robert E. KeETON†}

Using Rule 16 for testing and validating his theses, Professor Shapiro has opened our minds to rethinking some basic systemic assumptions about civil procedure and rulemaking. His paper illumines very large and significant issues. I share Professor Shapiro's inclination, when confronted with a cosmic question, to seek understanding through examination of particular instances.

My comments focus primarily on time constraints as controls over excesses both in trial and in pretrial development of cases. The parties may accept constraints by stipulation; in the absence of stipulation, rules or orders may impose them.

Associated with the larger storm of controversy over the amended Rule 16 are some whirlwinds (perhaps even tornadoes) of controversy over judicial behavior that has been labeled managerial judging.

Rule 16 itself focuses mostly upon just one part of judicial control over cases on a court's docket-judicial control over pretrial development of cases. The basic ideas advanced in Professor Shapiro's paper seem to me to be quite suggestive and promising, and worthy of examining also for the light they throw upon judicial initiative during the trial phase as distinguished from the pre-trial phase of a case history.

With a few notable exceptions (including the thoughtful contributions of John Langbein), pronouncements in praise or criticism of managerial judging have focused less on trial than on pretrial. In these few comments, I propose to place the emphasis on trial, and on how one's views about judicial control (or initiative, or management, or whatever you may wish to call it) will bear upon what happens in the trial. I do so in the belief that the expectations of judges and lawyers about the nature of the trial they anticipate (if the case turns out to be one of the $5 \%$ or so that go through trial) deeply affect what they do in Rule 16

+ Judge, United States District Court, District of Massachusetts; Langdell Professor Emeritus, Harvard Law School. B.B.A. 1940, LL.B. 1941, University of Texas; S.J.D. 1956, Harvard University. 
conferences and, more generally, throughout pretrial case development. Adversary trial was never meant to be the speediest form of trial. The aim, and the claim, has been and continues to be first in quality of disposition, not first in time.

Why, then, have the recent amendments to Rule 16 strongly encouraged, if not mandated, judicial intervention to promote disposition without trial? Have the framers of amendments narrowed Rule 1's triple focus on "just, speedy, and inexpensive determination of every action" to emphasize "speedy and inexpensive" even if that may cause outcomes to fall short of being "just" determinations?

Before we accept that interpretation, we should examine more closely the inherent incentives of different models of adversary trials.

It often happens in an adversary trial that one side has a greater incentive than the other to aim for conciseness and clarity. If lawyers expect that the judge will passively observe while an advocate with an interest in complicating and lengthening the trial works at that strategy, they are likely to engage in long, complicated, and contentious discovery. The advocate with an interest in complexity and length of trial also has an interest in testing the limits of tolerance of the judicial officer (judge, magistrate, or master) who oversees discovery.

Do rulemakers, or judges exercising inherent or prescribed functions, have the power to fashion alternative models of trial, not just alternatives to trial? If so, should that power be exercised? If the answer is yes, shall we develop new models in which the judge's role is different? Should the trial judge be more firmly in control of the method, length, and expense of the trial?

Why do some disputants who can afford to do so rent a judge? Judge shopping may be an element in the motivation, but probably a minor element in most instances. What counts more is that the parties are choosing a different, more streamlined, shorter model of trial, with a different role for the judge and different roles for the advocates. The judge's role may be defined formally by the terms of a stipulation to which the parties and the judge agree, or it may be incident to the known tendencies of the judge who is "rented" by agreement of disputants.

Why do the parties choose a shorter trial than the one that would occur before the judge to whom the legal system would otherwise assign their case? We should be examining that question seriously. The marketplace may be telling us something about perceptions of quality as well as perceptions of cost.

Rule $16(a)(5)$ says explicitly that the trial court "may in its discretion" call a conference for the purpose of "facilitating the settlement of 
the case."

Rule 16(c)(7) says explicitly "[t]he participants at any conference under this rule may consider and take action with respect to," among other things, the possibility of "use of extrajudicial procedures to resolve the dispute."

Observe that the rule says nothing explicitly about judicial as distinguished from extra-judicial alternative dispute resolution procedures.

Are trial judges supposed to read Rule 16 as implying (if not expressing) a prohibition against judicially-supervised alternatives to traditional adversary trials?

Professor Shapiro, after noting that an interest in a higher degree of uniformity of federal practice was an articulated purpose of the Federal Rules of Civil Procedure, observes that the rulemakers also "wanted to escape the rigidities and technicalities" of procedural codes. "The key, then," he adds, "was an increase in flexibility." Trial judges were to be liberated from, for example, some of the rigorous restraints of law, compared with equity, and allowed more discretion to get to the merits expeditiously and inexpensively.

Encouraged by Professor Shapiro's focus on flexibility, and not entirely discouraged by his perception that rulemakers held back from giving trial judges "express power to act coercively in any way not authorized" by other sources of authority, I am inclined to read Rule 16 as not prohibiting trial judges from calling a Rule 16 conference to consider a shorter and more sharply focused form of trial than the traditional-model adversary trial-a somewhat different model of adversary trial in which the redefined roles of the lawyers and the judge give the trial judge both power and responsibility to control excesses of traditional adversariness.

If you believe that the factfinder on disputed evidence will have a better understanding of the genuine disputes of material fact after a crisp, focused presentation spanning two days or two weeks than after a less focused presentation spanning two months, you may prefer a more streamlined model of adversary trial not merely on grounds of speed and lower cost but also on grounds of the expected quality of the decision.

Another significant theme Professor Shapiro observes in federal rulemaking is a "general endorsement of the adversary system and of party control of litigation," tempered by a reduction of some of the excesses of the traditional adversary system, including especially surprise and concealment.

After some experimentation, under stipulations of the parties, with both a one-day dispositive summary jury trial of a case that would have 
taken a week or two to try in the traditional way and several two-day conditionally dispositive trials of cases that would have taken two months or longer to try, I have this observation to report:

The time constraints placed upon the advocates gave them powerful incentives to discard techniques of lengthy direct and cross-examination of witnesses involving questions that were meant more to argue the case than to develop the testimony of the witnesses. Instead, they quoted selected passages from documents, depositions, and affidavits as they used their precious time to weave the evidence and argument together into crisp, clear presentations of their respective positions. Within reasonable limits and under reasonable controls, a shorter model of adversary trial may be better in quality of disposition-closer to the aim of a just determination-as well as speedier and less expensive.

I doubt, however, that it is possible to design such a shorter, better focused trial, without changing the trial judge's role to one of somewhat more rigorous control over the process than that implicit in the role of judge in the traditional adversary trial.

I doubt that the framers of Rule 16 in the 1930s or the framers of the 1983 amendment were thinking about this problem. Indeed, I believe that even the Federal Rules of Evidence, which surely are more centrally focused upon trial than are the Federal Rules of Procedure, do not have much to say that is relevant to this subject. The traditional adversary trial is ruled more by tradition than by rule.

Model changes may be harder to achieve when traditions must be changed than when only rules need be changed. But rules can make an important contribution. Rule 16 and its amendments, despite ambiguities and shortcomings, have advanced serious consideration of extrajudicial alternatives to traditional adversary trials. Whether meant to do so or not, they have also encouraged many judges and lawyers to think more seriously about judicially-supervised alternatives. Perhaps the time has come to give serious thought to changing rules in ways that will legitimate and encourage the development of judicially-supervised alternatives to traditional adversary trials.

You may have observed that I just used the term "judiciallysupervised."

"Managerial judging" evokes quite varied imagery. When a trial judge is identified by name in a law professor's article as a "managerial judge," she may be in doubt about whether the label is meant as a compliment or a criticism. Was the phrase meant to allude to "managing" prisons, hospitals, and schools, or "managing" pretrial development of cases, or "managing" settlement negotiations, or "managing" 
trials? And what kind of managing-intrusive, and perhaps by implicit threats of extralegal judicial behavior-or benign and constructive?

I have wondered whether I might suggest a more suitable phrase than "managerial judging" to describe the kind of behavior that would be appropriate in a judicially-supervised alternative to traditional adversary trial. As I was wondering a few days ago I reached for the handiest thesaurus and, under the entry for "Management," found three-quarters of a page of suggestive terms. How do you react to:

care and control,

stewardship over the trial,

superintendence,

regimen,

housekeeping,

administration,

bureaucracy, and

direction and leadership?

Or (bearing in mind the admiralty jurisdiction), pilotage?

Or (bearing in mind aviation as well as admiralty jurisdiction), the steering instrument, the joy-stick?

Or (going western, as my thesaurus did not), corralling? The judge as wrangler?

Or (in imagery recently evoked by Judge Selya ${ }^{\mathbf{1}}$ ), guru?

Or (in other imagery), manipulator, one who maneuvers, pulls the strings, keeps order, polices, regulates, and has a way with the parties and lawyers?

Or, one who channels? (Do you envision a clear, clean stream or a muddy gutter?)

Here's one I like-a shepherd.

Judge Weinstein remarked that federal judges might be encouraged to be sheep, led by academic shepherds. Would trial lawyers prefer academic shepherds, or perhaps no shepherds at all? Before answering this question, perhaps we should sharpen it. Will the answer lawyers give be different if they are not asked about their preferences in a particular case in which their roles have already been assigned, but about their preferences in a system in which each lawyer will sometimes be on the side that has incentives for simplicity and brevity and at other times on the side that has incentives for complexity and length?

${ }^{1}$ See In re San Juan Dupont Plaza Hotel Fire Litigation, 859 F.2d 1007, 1010 (1st Cir. 1988). 
Given provisions for sanctions like those of Rule 16, zealous trial advocates may enter the courtroom thinking, "We are officers of the court, who may be disciplined by the stern judge for any violations of Rules 11, 16, and 26, among others."

Envision, as an alternative, zealous trial advocates who enter the courtroom thinking, "Our judge is our shepherd. She leadeth us to a speedy and just determination of our case."

If we are not content to call good judicial behavior simply "judging," shall we call it shepherding the case, speedily and inexpensively, to the fold of justice?

More to the point, shall we revise our rules to legitimate and encourage more of that kind of judging, whatever it may be called? 